\title{
Application of MIMO Disturbance Observer to Control of an Electric Wheelchair Using NSGA-II
}

\author{
Mohammad Nasser Saadatzi, Javad Poshtan, Mohammad Sadegh Saadatzi ${ }^{1}$ \\ Department of Electrical Engineering, Iran University of Science and Technology, Tehran, Iran, ${ }^{1}$ Department of Mechanical Engineering, \\ Multimedia University, Kuala Lumpur, Malaysia
}

\section{A B S T R A C T}

Electric wheelchairs (EW) experience various terrain surfaces and slopes as well as occupants with diverse weights. This, in turn, imparts a substantial amount of perturbation to the EW dynamics. In this paper, we make use of a two-degree-of-freedom control architecture called disturbance observer (DOB) which reduces sensitivity to model uncertainties, while enhancing rejection of disturbances caused due to entering slopes. The feedback loop which is designed via characteristic loci method is then augmented with a DOB with a parameterized low-pass filter. According to disturbance rejection, sensitivity reduction, and noise rejection of the whole controller, three performance indices are defined which enable us to pick the filter's optimal parameters using a multi-objective optimization approach called non-dominated sorting genetic algorithm-II. Finally, experimental results show desirable improvement in stiffness and disturbance rejection of the proposed controller as well as its robust stability.

Key words: Electric wheelchair, disturbance observer, multi-objective optimization, NSGA-II, characteristic loci method

\section{INTRODUCTION}

Electric wheelchair (EW) applications are growing as a consequence of the increase in population of the elderly as well as accidents. ${ }^{[1]}$ EWs face occupants with various weights, and moveover, diverse terrain surfaces and slopes which, in turn, introduce a substantial amount of perturbation to the EW's dynamics. Nevertheless, users who are mostly mobility-impaired patients and/ or elderlies demand reliable and smooth driving conditions.

Majority of EWs in the market are those in which linear and angular velocities are to be controlled and their corresponding reference inputs are commanded using a man-machine interface (e.g., joystick). Some papers have suggested controllers for this problem using miscellaneous algorithms like adaptive controllers, ${ }^{[2,3]}$ neural control techniques,,$^{[4-8]}$ robust controllers, ${ }^{[9-11]}$ etc. ${ }^{[12,13]}$ Some of these papers have dealt with the EW's uncertainties including variation in the user's weight and/or the surface underneath the EW and some of them with slopes. ${ }^{[14]}$ In the current paper, however, we shall be dealing with any perturbation in the EW dynamics and the functioning environment in a unified approach including the occupant's unknown weight, varying terrain surface, and slopes existing in the path. These perturbations cause two major problems for the user: (i) Any little change during the trip including slopes, bumps, and surface change turns into variation in the regulated linear and angular velocities of the EW. This, in turn, means that the user needs to be so cautious and act so fast when something occurs. So, the first aim of this paper is to improve rejection of these disturbances.

(ii) Since the physical conditions of the probable user are unknown for an EW manufacturer, one important goal for the controller is to reduce the sensitivity of the closed-loop dynamics to the uncertainties in the EW system, which is indeed the other objective in the current research.

In the present paper, EW's dynamics considering its movements on slopes are developed and dealt with a twodegree-of-freedom control architecture, i.e. disturbance observer (DOB), which reduces sensitivity of closed-loop system to model uncertainties and takes care of rejection of the disturbances caused by moving on slopes as well. . $^{15-19]}$

In DOB systems, a low-pass filter $\mathrm{Q}$ is responsible for the causality and relates to several characteristics of the system. Some papers have suggested a set of guidelines about how to design the $\mathrm{Q}$ filter so that the desired characteristics are satisfied. ${ }^{[20,21]}$ These guidelines, however, are either for low-order Single-input-single-output (SISO) plants or not systematic enough. Thus, selection of these parameters for 
the EW DOB system using those guidelines turns into an ad hoc process. To avoid this, in this paper, three performance indices are established according to disturbance rejection, stiffness, and noise reduction of the control system. An multi-objective optimization (MOO) approach using non-dominated sorting genetic algorithm-II (NSGA-II) is employed to automatically look up optimal parameters in $\mathrm{Q}$ including the time constants, numerator, and denominator orders of two Butterworth-like filters.

At last, experimental results confirm considerable improvement in the controller stiffness against EW's uncertainties, rejection of disturbances, and robust stability. The constructed wheelchair is shown in Figure 1.

\section{DYNAMIC MODELING}

A simplified mechanism of our EW, moving upwards on a slope, is illustrated in Figure 2. $\mathrm{P}_{0}$ is the middle point of rare axle. In our EW, the motors are coupled to the rear wheels through chain pulley systems. Using the principle of conservation of moments throughout a rigid body, the component of gravitational force along the surface could be expressed as resistant torque. Parameters and symbols needed during the paper along with their definitions are gathered in Table 1.

Note that subscripts 1 and $r$ refer to the left side and right side of the EW, respectively. Schematic of our EW's propelling system is illustrated in Figure 3.

According to Figures 2 and 3, if the fundamental electrical and mechanical equations of the motors are considered, a state-space representation of the system can be written as

$$
\begin{aligned}
& \dot{x}(t)=A x(t)+B E(t)+D \delta(t), \\
& x(t)=\left(i_{1}(t), \omega_{1}(t), i_{r}(t), \omega_{r}(t)\right)^{T}, \\
& E(t)=\left(e_{1}(t), e_{r}(t)\right)^{T}, \\
& \delta(t)=\sin (\alpha(t)),
\end{aligned}
$$

$\mathrm{A}=\left[\begin{array}{cccc}-\mathrm{R}_{1} / \mathrm{L}_{1} & -\mathrm{nk}_{\mathrm{el}} / \mathrm{L}_{1} & 0 & 0 \\ \mathrm{k}_{\mathrm{t} 1} / \mathrm{nJ}_{1} & -\mathrm{B}_{1} / \mathrm{J}_{1} & 0 & 0 \\ 0 & 0 & -\mathrm{R}_{\mathrm{r}} / \mathrm{L}_{\mathrm{r}} & -\mathrm{nk}_{\mathrm{er}} / \mathrm{L}_{\mathrm{r}} \\ 0 & 0 & \mathrm{k}_{\mathrm{tr}} / \mathrm{nJ}_{\mathrm{r}} & -\mathrm{B}_{\mathrm{r}} / \mathrm{J}_{\mathrm{r}}\end{array}\right]$,

$B=\left[\begin{array}{cc}1 / L_{1} & 0 \\ 0 & 0 \\ 0 & 1 / L_{r} \\ 0 & 0\end{array}\right]$,

\begin{tabular}{ll}
\hline Table I: Model parameters and symbols \\
\hline Symbol & Quantity \\
\hline$\alpha$ & Slope angle \\
$m$ & Total weight of the EW including occupant \\
$\omega$ & Angular velocity of the wheel \\
$k_{\mathrm{t}}$ & Torque constant of the motor \\
$k_{\mathrm{e}}$ & Back EMF constant of the motor \\
$L_{\mathrm{a}}$ & Wiring inductance of the motor \\
$R_{\mathrm{a}}$ & Wiring resistance of the motor \\
$J$ & Inertia of the combination of the motor, load, and \\
$B$ & gearbox referred to the motor shaft \\
& Viscous-friction coefficient of the combination of the \\
$\mathrm{e}$ & motor, load, and gearbox referred to the motor shaft \\
$R$ & Input voltage of the motor \\
$W$ & Wheel radius \\
$n$ & Rear wheelbase of the EW \\
EW - Electric wheelchairs; & EMF - Electromagnetic force
\end{tabular}

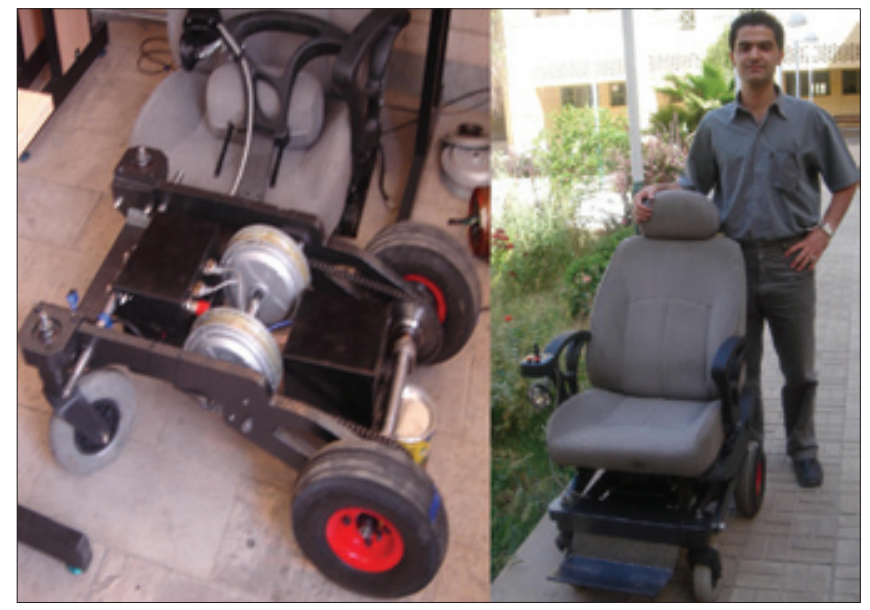

Figure I: The electric wheelchair constructed in order to experimentally verify the proposed control method

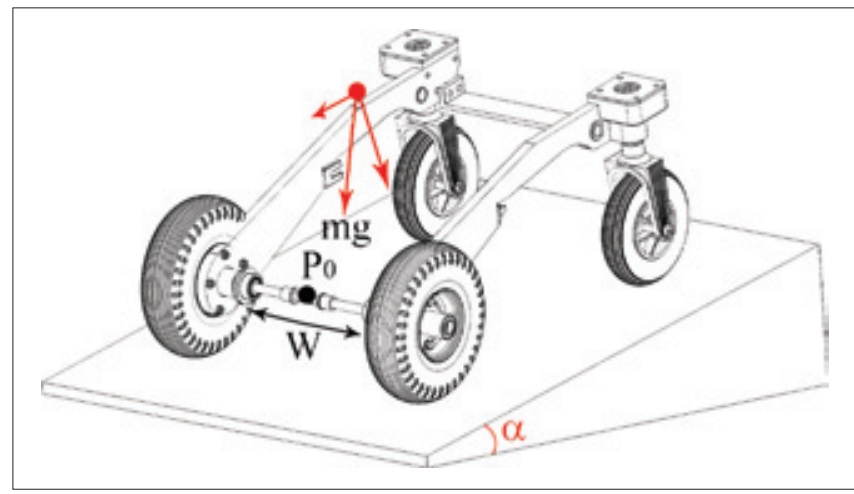

Figure 2: EW's chassis moving upward a slope and exerting forces caused by weight

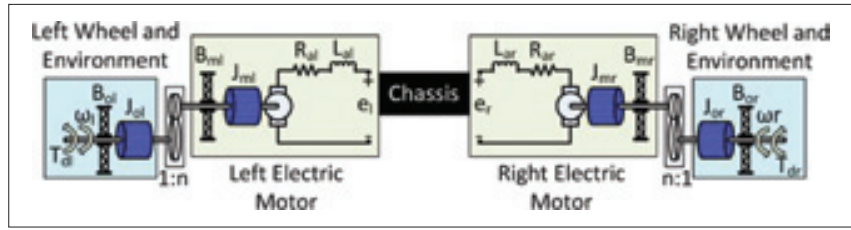

Figure 3: The EW's propelling system schematic 
$D=\left[\begin{array}{c}0 \\ -\mathrm{mgR}_{1} / 2 \mathrm{n}^{2} \mathrm{~J}_{1} \\ 0 \\ -\mathrm{mgR}_{\mathrm{r}} / 2 \mathrm{n}^{2} \mathrm{~J}_{\mathrm{r}}\end{array}\right]$.

The EW's angular velocity $\Omega$ and linear velocity $V$ are obtained as

$\mathrm{V}=\frac{\mathrm{R}_{\mathrm{r}}}{2} \omega_{\mathrm{r}}+\frac{\mathrm{R}_{1}}{2} \omega_{1}$

$\Omega=\frac{\mathrm{R}_{\mathrm{r}}}{\mathrm{W}} \omega_{\mathrm{r}}-\frac{\mathrm{R}_{1}}{\mathrm{~W}} \omega_{1}$.

For detailed information on EW kinematics refer to. ${ }^{[10]}$ One can release EW's multivariable dynamic equations in frequency domain by combining (1) to (8) as follows.

$\left[\begin{array}{c}V(s) \\ \Omega(s)\end{array}\right]=\mathrm{G}(\mathrm{s}) \mathrm{E}(\mathrm{s})+\mathrm{P}(\mathrm{s}) \delta(\mathrm{s})$

$\mathrm{g}_{11}(\mathrm{~s})=\frac{\mathrm{R}_{\mathrm{l}} \mathrm{K}_{\mathrm{tl}} / 2 \mathrm{n}}{\left(\mathrm{L}_{\mathrm{al}} \mathrm{s}+\mathrm{R}_{\mathrm{al}}\right)\left(\mathrm{J}_{\mathrm{l}} \mathrm{S}+\mathrm{B}_{\mathrm{l}}\right)+\mathrm{K}_{\mathrm{tl}} \mathrm{K}_{\mathrm{el}}}$

$\mathrm{g}_{12}(\mathrm{~s})=\frac{\mathrm{R}_{\mathrm{r}} \mathrm{K}_{\mathrm{tr}} / 2 \mathrm{n}}{\left(\mathrm{L}_{\mathrm{ar}} \mathrm{s}+\mathrm{R}_{\mathrm{ar}}\right)\left(\mathrm{J}_{\mathrm{r}} \mathrm{s}+\mathrm{B}_{\mathrm{r}}\right)+\mathrm{K}_{\mathrm{tr}} \mathrm{K}_{\mathrm{er}}}$

$\mathrm{g}_{21}(\mathrm{~s})=\frac{-\mathrm{R}_{\mathrm{l}} \mathrm{K}_{\mathrm{tl}} / \mathrm{nW}}{\left(\mathrm{L}_{\mathrm{al}} \mathrm{s}+\mathrm{R}_{\mathrm{al}}\right)\left(\mathrm{J}_{\mathrm{l}} \mathrm{s}+\mathrm{B}_{\mathrm{l}}\right)+\mathrm{K}_{\mathrm{tl}} \mathrm{K}_{\mathrm{el}}}$

$\mathrm{g}_{22}(\mathrm{~s})=\frac{\mathrm{R}_{\mathrm{r}} \mathrm{K}_{\mathrm{tr}} / \mathrm{nW}}{\left(\mathrm{L}_{\mathrm{ar}} \mathrm{s}+\mathrm{R}_{\mathrm{ar}}\right)\left(\mathrm{J}_{\mathrm{r}} \mathrm{s}+\mathrm{B}_{\mathrm{r}}\right)+\mathrm{K}_{\mathrm{tr}} \mathrm{K}_{\mathrm{er}}}$

$\mathrm{p}_{11}(\mathrm{~s})=\frac{-\mathrm{mg}}{2 \mathrm{n}}\left(\frac{\mathrm{R}_{1}\left(\mathrm{~L}_{\mathrm{al}} \mathrm{s}+\mathrm{R}_{\mathrm{al}}\right)}{\mathrm{K}_{\mathrm{tl}}} \mathrm{g}_{11}+\frac{\mathrm{R}_{1}\left(\mathrm{~L}_{\mathrm{ar}} \mathrm{s}+\mathrm{R}_{\mathrm{ar}}\right)}{\mathrm{K}_{\mathrm{tr}}} \mathrm{g}_{12}\right)$

$\mathrm{p}_{12}(\mathrm{~s})=\frac{-\mathrm{mg}}{2 \mathrm{n}}\left(\frac{\mathrm{R}_{\mathrm{l}}\left(\mathrm{L}_{\mathrm{al}} \mathrm{s}+\mathrm{Ral}\right)}{\mathrm{K}_{\mathrm{tl}}} \mathrm{g}_{21}+\frac{\mathrm{R}_{\mathrm{r}}\left(\mathrm{L}_{\mathrm{ar}} \mathrm{s}+\mathrm{R}_{\mathrm{ar}}\right)}{\mathrm{K}_{\mathrm{tr}}} \mathrm{g}_{22}\right)$

In, ${ }^{[10]}$ decoupling of the EW's multivariable dynamics was addressed by analytical decomposition of matrix G. It was shown that high degree of diagonal dominance can be achieved using $\beta^{-1}$, where $\beta$ is a constant matrix as

$\beta=\left[\begin{array}{cc}1 / 2 & 1 / 2 \\ -1 / W & 1 / W\end{array}\right]$

Compensation of the EW's inputs with $\beta^{-1}$ leads to a new transfer-function matrix (TFM) H with inputs u as below.

$\mathrm{H}(\mathrm{s}) \triangleq \mathrm{G}(\mathrm{s}) \beta^{-1}$

$\mathrm{u}(\mathrm{s})=\left[\begin{array}{c}\mathrm{u}_{1}(\mathrm{~s}) \\ \mathrm{u}_{2}(\mathrm{~s})\end{array}\right] \triangleq \beta \mathrm{E}(\mathrm{s})=\left[\begin{array}{c}\left(\mathrm{e}_{\mathrm{l}}(\mathrm{s})+\mathrm{e}_{\mathrm{r}}(\mathrm{s})\right) / 2 \\ \left(\mathrm{e}_{\mathrm{l}}(\mathrm{s})-\mathrm{e}_{\mathrm{r}}(\mathrm{s})\right) / \mathrm{W}\end{array}\right]$

In the rest of this paper, the pre-compensated system- with $\mathrm{H}$ as its TFM and $\mathrm{u}$ as its input vector-is considered as the system to be identified and be controlled. $\operatorname{In}^{[10]}$ it is proved that there are some advantages as consequences of this assumption including: (i) $\mathrm{H}$ is much more diagonally dominant compared to $\mathrm{G}$ and (ii) estimation of $\mathrm{H}$ using $\mathrm{u}$ results in a more accurate system identification, since it reveals motors mutual effects on each other. Elements of the EW's nominal plant $\mathrm{H}$ which estimated using the method developed in our previous paper, ${ }^{[10]}$ while the occupant weighs $120 \mathrm{~kg}$ and the EW is driven through a grass-covered field are

$h_{11}=\frac{2.59 * 10^{-2}(1+0.11 s)}{(1+s)(1+0.1 s)}$,

$h_{12}=\frac{0.47^{*} 10^{-3}(1+0.04 \mathrm{~s})}{(1+1.03 \mathrm{~s})(1+0.07 \mathrm{~s})}$

$h_{21}=\frac{2.46^{*} 10^{-3}(1+0.06 \mathrm{~s})}{(1+0.2 \mathrm{~s})(1+1.14 \mathrm{~s})}$

$h_{22}=\frac{2.11^{*} 10^{-2}(1+1.28 \mathrm{~s})}{(1+0.71 \mathrm{~s})(1+1.143 \mathrm{~s})}$

\section{CONTROL SYSTEM REQUIREMENTS}

Some criteria for the closed-loop system are established according to ride comfort, maneuverability and safety: (i) under-damped responses result in undesired longitudinal vibrations which affect ride comfort. Maximum overshoot, hence, is defined as $M_{p}<\% 1$. (ii) Acceptable maneuverability requires us to speed up the responses as much as it has no influence on ride comfort. Rise time is defined as $t_{r}<2$ s. (iii) $\Omega$ would vary if its interaction with $\mathrm{V}$ is not properly removed and the system encounters with a disturbance in V. Variation in $\Omega$ turns into variation in the EW's heading direction which may cause hitting to obstacles. So in order to strengthen safety the interaction has to be removed.

\section{Controller Design}

The DOB is generally used as an add-on block to the main controller to form a two-degree-of-freedom control architecture. The DOB improves disturbance rejection performance of the control system as well as its stiffness. It has the form shown in Figure 4, where $Q$ is the low pass filter, $\mathrm{z}$ is the main controller output, and $\eta$ is the sensor noise. Also, $\phi$ is a signal corresponding to perturbation.

In Figure 4, transfer functions (TF) from three external inputs $(\mathrm{z}, \delta, \eta)$ and perturbation $(\phi)$ to output $(\mathrm{y})$ is obtained as:

$\mathrm{y}=\mathrm{H}_{\mathrm{n}} \mathrm{Z}+\left(\mathrm{I}-\mathrm{H}_{\mathrm{n}} \mathrm{QH}_{\mathrm{n}}^{-1}\right) \mathrm{P} \delta-\mathrm{H}_{\mathrm{n}} \mathrm{QH}_{\mathrm{n}}^{-1} \eta+\mathrm{H}_{\mathrm{n}}(\mathrm{I}-\mathrm{Q}) \varphi$. 


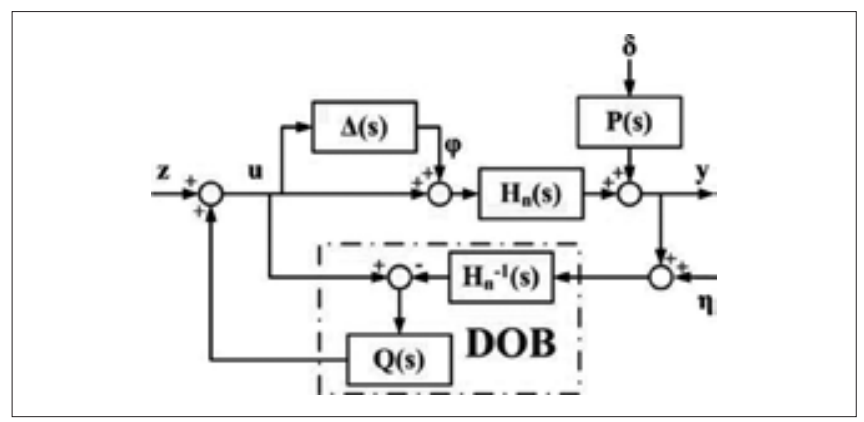

Figure 4: Basic structure of disturbance observer

If $\mathrm{Q} \rightarrow \mathrm{I}$ in low frequencies, then (24) approximately equals to

$\mathrm{y} \approx \mathrm{H}_{\mathrm{n}} \mathrm{Z}-\eta$.

In other words, in low frequencies, the DOB rejects the disturbance and forces the input-output behavior of the system to be like the nominal plant (affected only by the measurement noise). This is the desired property of the DOB in the current research, so that it can be utilized to reject the disturbances caused by moving on slopes. Furthermore, the aforementioned uncertainties disappear and do not annoy the characteristic loci method (CLM) design procedure. The CLM can efficiently be exploited to design a controller for nominal plant without concern of sensitivity to perturbations. In the next subsection, the main controller design is explained using the CLM.

\section{Main Controller Design Using the CLM}

The characteristic loci of a square $\mathrm{p} \times \mathrm{pH}(\mathrm{s})$ are $\mathrm{p}$ eigenvalues of $\mathrm{H}(\mathrm{s}), \lambda_{1}(\mathrm{~s}), \ldots, \lambda_{\mathrm{p}}(\mathrm{s})$, and characteristic directions are $\mathrm{p}$ corresponding eigenvectors, $\mathrm{w}_{1}(\mathrm{~s}), \ldots, \mathrm{w}_{\mathrm{p}}(\mathrm{s})$. Spectral decomposition of $\mathrm{H}(\mathrm{s})$ is obtained as follows.

$\mathrm{W}(\mathrm{s}) \triangleq\left[\mathrm{w}_{1}(\mathrm{~s}) \quad \ldots \quad \mathrm{w}_{\mathrm{p}}(\mathrm{s})\right]$,

$\Lambda(\mathrm{s}) \triangleq \operatorname{diag}\left(\lambda_{1}(\mathrm{~s}), \ldots, \lambda_{\mathrm{p}}(\mathrm{s})\right)$,

$\mathrm{H}(\mathrm{s})=\mathrm{W}(\mathrm{s}) \Lambda(\mathrm{s}) \mathrm{W}^{-1}(\mathrm{~s})$.

If the controller $K(\mathrm{~s})$ is given the same eigenvectors as $\mathrm{H}(\mathrm{s})$ the plant and the controller commute, i.e. $\mathrm{H}(\mathrm{s}) \mathrm{K}(\mathrm{s})=\mathrm{K}(\mathrm{s}) \mathrm{H}(\mathrm{s})$. If characteristic loci of the controller are $\mu_{1}(\mathrm{~s}), \ldots, \mu_{\mathrm{p}}(\mathrm{s})$, then

$\mathrm{K}(\mathrm{s})=\mathrm{W}(\mathrm{s}) \operatorname{diag}\left(\mu_{1}(\mathrm{~s}), \ldots, \mu_{\mathrm{p}}(\mathrm{s})\right) \mathrm{W}^{-1}(\mathrm{~s})$,

$\mathrm{T}(\mathrm{s})=\mathrm{W}(\mathrm{s}) \operatorname{diag}\left(\frac{\mu_{1}(\mathrm{~s}) \lambda_{1}(\mathrm{~s})}{1+\mu_{1}(\mathrm{~s}) \lambda_{1}(\mathrm{~s})}, \ldots, \frac{\mu_{\mathrm{p}}(\mathrm{s}) \lambda_{\mathrm{p}}(\mathrm{s})}{1+\mu_{\mathrm{p}}(\mathrm{s}) \lambda_{\mathrm{p}}(\mathrm{s})}\right) \mathrm{W}^{-1}(\mathrm{~s})$,

where $\mathrm{T}$ is the closed-loop TFM. Unfortunately, the elements of $\mathrm{W}(\mathrm{s})$ (and therefore $\mathrm{W}^{-1}(\mathrm{~s})$ ) are almost always irrational functions with no practical realizations. Consequently, real constant approximations to $\mathrm{W}(\mathrm{s})$ and $\mathrm{W}^{-1}(\mathrm{~s})$ at some specified frequencies are chosen instead. This leads to an approximate commutative controller which is calculated through ALIGN algorithm (AA). ${ }^{[22]}$ In the CLM, the controller design is accomplished in three consecutive steps briefly described below.

\section{High-Frequency Compensation}

According to (30), high gain can be used to remove interactions, i.e.

$\left|\mu_{\mathrm{i}}(\mathrm{s}) \lambda_{\mathrm{i}}(\mathrm{s})\right| \gg 1$, for each $\mathrm{i} \Rightarrow \mathrm{T}(\mathrm{s}) \approx \mathrm{I}_{\text {pxp }}$.

Beyond some frequency, however, high gain is impractical due to physical reasons and stability requirements. So at a high frequency $\omega_{h}$, return ratio is decoupled via a constant matrix $K_{h}$, which in fact, is a real approximation of $\mathrm{H}^{-1}\left(j \omega_{h}\right)$. This work which can be well done by AA compels the closedloop system in the vicinity of $\omega_{h}$ to approach unity. Since contributions of characteristic loci at frequencies much higher than cross-over frequency $\omega_{c}$ are low, high frequency decoupling is attempted near $\omega_{c}$. The decoupling matrix is resulted by performing AA at $\omega_{\mathrm{h}}=3 \mathrm{rads}^{-1}$.

$\mathrm{K}_{\mathrm{h}}=\operatorname{ALIGN}(\mathrm{H}(\mathrm{j} 3))=\left[\begin{array}{cc}125.18 & -2.22 \\ -8.1 & 128.74\end{array}\right]$

Applying $\mathrm{K}_{\mathrm{h}}$ reduces the interaction at $\omega_{\mathrm{h}}$ by $52 \%$ and $89 \%$ in the first and the second column, respectively.

\section{Medium-Frequency Compensation}

An approximate commutative controller $\mathrm{K}_{\mathrm{m}}(\mathrm{s})$ is designed at $\omega_{\mathrm{m}}=1 \mathrm{rads}^{-1}$ for the compensated plant $\mathrm{HK}_{\mathrm{k}}$, such that the decoupling performed at $\omega_{\mathrm{h}}$ is not affected considerably. $A_{m}$, real approximation of left eigenvector of $\mathrm{HK}_{\mathrm{k}}$ at $\omega_{\mathrm{m}}$, is calculated using AA. $\mathrm{M}_{\mathrm{m}}(\mathrm{s})$, a diagonal matrix with phase-lag elements, is designed to shape characteristic loci of $\mathrm{H}$ near $\omega_{c}$ in order to adjust required transient features and stability margins.

$$
\begin{aligned}
& A_{m}=\left[\begin{array}{cc}
1.03 & 7.8 * 10^{-3} \\
-0.26 & 1
\end{array}\right] \\
& \mathrm{M}_{\mathrm{m}}(\mathrm{s})=\left[\begin{array}{cc}
\frac{3.5(1+\mathrm{s})}{(1+10 \mathrm{~s})} & 0 \\
0 & \frac{4.5(1+\mathrm{s})}{(1+10 \mathrm{~s})}
\end{array}\right]
\end{aligned}
$$

\section{Low-Frequency Compensation}

This step aims to remove steady-state interaction in addition to steady-state error of step response. Elements of the designed diagonal matrix are Proportional-Integral (PI) compensators. To ensure that they do not disturb the previous adjustments too much, their gains and phases near and over $\omega_{\mathrm{m}}$ should be almost $0 \mathrm{~dB}$ and $0 \mathrm{rads}^{-1}$, respectively.

$\mathrm{K}_{\mathrm{l}}(\mathrm{s})=\left(1+\frac{1}{10 \mathrm{~s}}\right) \mathrm{I}_{2 \times 2}$ 
The main controller is obtained as a series connection of five matrices, one for achieving DD at high frequencies and four matrices for shaping characteristic loci by adding phase-lag and PI actions as

$K(s)=K_{h} K_{m}(s) K_{l}(s)=K_{h} A_{m} M_{m}(s) A_{m}^{-1} K_{l}(s)$.

\section{Optimal DOB Design}

The whole system including $K(\mathrm{~s})$ as the main controller is depicted in Figure 5. One can obtain TFs from three external inputs $(\mathrm{r}, \delta, \eta)$ and perturbation $(\phi)$ to output (y) as

$$
\begin{aligned}
y= & \left(I+H_{n} K\right)^{-1} H_{n} K_{r}+\left(I+H_{n} K\right)^{-1}\left(I-H_{n} Q H_{n}^{-1}\right) P \delta- \\
& \left(I+H_{n} K\right)^{-1} H_{n}\left(K+Q H_{n}^{-1}\right) \eta+\left(I+H_{n} K\right)^{-1} H_{n}(I-Q) \varphi .
\end{aligned}
$$

Low-frequency dynamics and high-frequency magnitude of $\mathrm{Q}$ should be kept close to unity and zero matrices, respectively. In this paper, its structure is considered as

$\mathrm{Q}(\mathrm{s})=\operatorname{diag}\left(\mathrm{q}\left(\mathrm{n}_{1}, \mathrm{~m}_{1}, \tau_{1}, \mathrm{~s}\right), \mathrm{q}\left(\mathrm{n}_{2}, \mathrm{~m}_{2}, \tau_{2}, \mathrm{~s}\right)\right)$

$\mathrm{q}(\mathrm{n}, \mathrm{m}, \tau, \mathrm{s})=\frac{\sum_{\mathrm{i}=0}^{\mathrm{n}} \mathrm{a}_{\mathrm{mi}}(\tau \mathrm{s})^{\mathrm{i}}}{(\tau \mathrm{s}+1)^{\mathrm{m}}}$,

where $\mathrm{n}$ is the numerator order, $\mathrm{m}$ the denominator order, $\tau$ is the filter time constant, and $\mathrm{a}_{\mathrm{mi}}=\mathrm{m} ! /(\mathrm{m}-\mathrm{i}) ! \mathrm{i}$ ! the binomial coefficient. $\mathrm{Q}$ becomes a low-pass filter, if $\mathrm{m}$ is selected to be strictly greater than $n$.

According to (37), we propose three fitness functions in order to improve control system characteristics. To achieve acceptable rejection of the disturbances caused due to entering and moving through slopes, the following equation should be small.

$\mu_{\delta}=\int_{0}^{\omega b} \sigma_{\max }\left(\mathrm{F}_{\delta}\left(\mathrm{I}+\mathrm{H}_{\mathrm{n}} \mathrm{K}\right)^{-1}\left(\mathrm{I}-\mathrm{H}_{\mathrm{n}} \mathrm{QH}_{\mathrm{n}}^{-1}\right) \mathrm{P}\right) \mathrm{d} \omega$

F which is a weighting function along with the end limits of integral give desired frequencies more influence on the index. Similarly, in order to filter out the sensor noise the TF from $\eta$ to y should set to be small. The measurement noise, however, affects the control input u more seriously than the output $y$ because the EW system has the characteristics of low pass filters. The TF from $\eta$ to $y$ in Figure 5 is,

$\mathrm{T}_{\eta \mathrm{u}}=-\left(\mathrm{I}+\mathrm{KH}_{\mathrm{n}}\right)^{-1}\left(\mathrm{~K}+\mathrm{QH}^{-1}\right)$

Therefore, the next fitness function is suggested as:

$\mu_{\eta}=\int_{\omega_{\mathrm{b}}}^{10 \omega_{\mathrm{b}}} \sigma_{\max }\left(\mathrm{F}_{\eta}\left(\mathrm{I}+\mathrm{KH}_{\mathrm{n}}\right)^{-1}\left(\mathrm{~K}+\mathrm{QH}^{-1}\right)\right) \mathrm{d} \omega$

Finally, to have higher system stiffness, the last term in (37) should be weakened. The last fitness function is suggested as

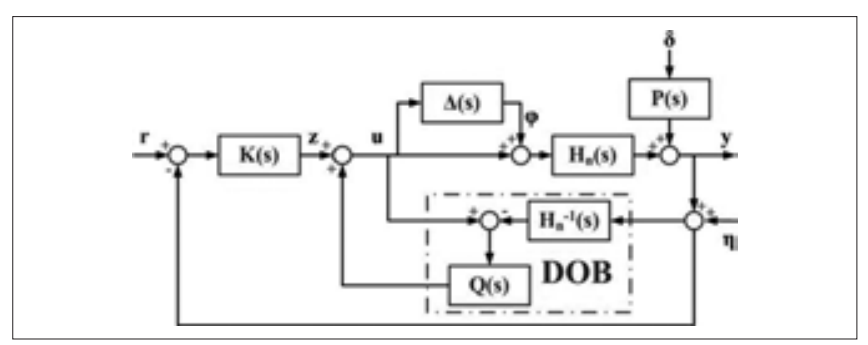

Figure 5: Two-degree-of-freedom structure including the main controller $\mathrm{K}(\mathrm{s})$ and the DOB

$\mu_{\varphi}=\int_{0}^{\omega_{\mathrm{b}}} \sigma_{\max }\left(\mathrm{F}_{\varphi}\left(\mathrm{I}+\mathrm{H}_{\mathrm{n}} \mathrm{K}\right)^{-1} \mathrm{H}_{\mathrm{n}}(1-\mathrm{Q})\right) \mathrm{d} \omega$

Before we proceed to finding the optimal values of the Q filter's parameters using any optimization method, we need to specify the extreme values each of them can hold. In (38), the parameters which play the most important role are the time constants. They bear, obviously, direct effects in stability, performance, and noise issues. A very subtle effect of theirs, however, is associated with the energy consumption and the issues related to actuators saturation. In Figure 5, if we incorporate the uncertainty block, $\Delta(\mathrm{s})$, to the nominal system, $\mathrm{H}_{\mathrm{n}}(\mathrm{s})$, and name the whole system as $\mathrm{H}(\mathrm{s})$, one can find the transfer function from $r$ to the actuator signal, $u$, is as follows.

$\mathrm{u}_{\mathrm{r}}=\left(\mathrm{I}+\mathrm{Q}\left(\mathrm{H}_{\mathrm{n}}^{-1} \mathrm{H}-1\right)+\mathrm{KH}\right)^{-1} \mathrm{Kr}$

In (44), if $\mathrm{Q}$ is substituted by zero matrix, which means no disturbance observer, we get to the equation of the simple feedback architecture. Thus, any difference in the actuator amplitude after introducing the DOB block is a result of the term $\mathrm{Q}\left(\mathrm{H}_{\mathrm{n}}^{-1} \mathrm{H}-\mathrm{I}\right)$. Since $\mathrm{H}$ is most different from $\mathrm{H}_{\mathrm{n}}$ in the high frequency band, the term $\left(\mathrm{H}_{\mathrm{n}}^{-1} \mathrm{H}-\mathrm{I}\right)$ has its most energy in that band. Therefore, if $\mathrm{Q}$ is chosen to be very small in high frequency band, by choosing appropriate time constants, the term $\mathrm{Q}\left(\mathrm{H}_{\mathrm{n}}^{-1} \mathrm{H}-\mathrm{I}\right)$ does not affect (44) considerably. The transfer function from $\delta$ to $u$ is,

$\mathrm{u}_{\delta}=-\left(\mathrm{I}+\mathrm{Q}\left(\mathrm{H}_{\mathrm{n}}^{-1} \mathrm{H}-1\right)+\mathrm{KH}\right)^{-1}\left(\mathrm{~K}+\mathrm{QH}_{\mathrm{n}}^{-1}\right) \mathrm{P} \delta$

In (45), similarly, since $\mathrm{H}$ has its most energy in the high frequency band both terms $\mathrm{Q}\left(\mathrm{H}_{\mathrm{n}}^{-1} \mathrm{H}-\mathrm{I}\right)$ and $\mathrm{QH}_{\mathrm{n}}^{-1}$ are negligible providing that the time constants of $\mathrm{Q}$ are selected small enough. Otherwise, in face of sudden disturbances or sudden changes in reference command, the actuator signals will increase which could cause saturation.

For the limits on denominator degrees of $\mathrm{Q}, \mathrm{m}_{1}$, and $\mathrm{m}_{2}$, it is noteworthy that the greater they are the more complex the controller becomes, which in turn means a faster processor will be needed. The limits on the numerator degrees are automatically determined by the casualty condition of the controller. For total controller causality, the constraint $m_{1}+m_{2}-\left(n_{1}+n_{2}\right)>3$ also has to be satisfied. 
MOO is the problem of simultaneously optimizing two or more conflicting objectives with specific constraints. Here, Pareto-based multi-objective approach is used to address the issue. In mathematical terms, the multi-objective problem can be formulated as

$\min _{\mathrm{x}}\left[\mu_{1}(\mathrm{x}), \mu_{2}(\mathrm{x}), \ldots \mu_{\mathrm{n}}(\mathrm{x})\right]^{\mathrm{T}}$

$\mathrm{x}_{\mathrm{i}, \min } \leq \mathrm{x}_{\mathrm{i}} \leq \mathrm{x}_{\mathrm{i}, \max }$ for $\mathrm{i}=1, \ldots, \mathrm{n}$,

$\mathrm{g}(\mathrm{x}) \leq 0, \mathrm{~h}(\mathrm{x})=0$,

where $\mu_{\mathrm{i}}$ is the $\mathrm{i}$-th objective function, $\mathrm{g}$ the inequality constraint, $h$ the equality constraint, and $x$ the vector of optimization or decision variables. The problem solution is a set of Pareto points for which betterment in one objective can only take place with the worsening of at least another objective.

Evolutionary algorithms are very famous methods in Multi-objective Optimization. Genetic algorithms such as NSGA-II and strength Pareto evolutionary approach 2 (SPEA-2) are common methods. The objective approach of solving multi-objective problems needs a Paretocompliant ranking method, favoring non-dominated solutions. In a problem with more than one objective function, there are two possibilities for any two solutions $\mathrm{x}_{1}$ and $\mathrm{x}_{2}$ : One dominates the other or none dominates the other. If both the following conditions hold a solution $x_{1}$ dominates $\mathrm{x}_{2}$ : (i) the solution $\mathrm{x}_{1}$ is not worse than $\mathrm{x}_{2}$ among all objectives and (ii) is strictly better than $\mathrm{x}_{2}$ in at least one objective. The following explains a step-by-step approach for NSGA-II. ${ }^{\mid 23]}$

1. Combine parent and offspring populations and construct $R_{t}=P_{t} \cup Q_{t}$. Do non-dominate sorting to $R_{t}$ and identify different fronts: $F_{i}, i=1,2$, etc.

2. Set new population $P_{t+1}=0$. Set a counter $i=1$. Until $\left|\mathrm{P}_{\mathrm{t}+1}\right|+\mathrm{F}_{\mathrm{i}}<\mathrm{N}\left(\mathrm{N}\right.$ is size of $\mathrm{P}_{\mathrm{t}}$ ) perform $\mathrm{P}_{\mathrm{t}+1}=\mathrm{P}_{\mathrm{t}+1}+\mathrm{F}_{\mathrm{i}}$ and $\mathrm{i}=\mathrm{i}+1$.

3. If $\left|\mathrm{P}_{\mathrm{t}+1}\right|+\mathrm{F}_{\mathrm{i}}>\mathrm{N}$, perform the crowding-sort procedure and include the most widely spread $\left(\mathrm{N}-\left|\mathrm{P}_{\mathrm{t}+1}\right|\right)$ solutions using the crowding distance value in sorted $\mathrm{F}_{\mathrm{i}}$ to $\mathrm{P}_{\mathrm{t}+1}$.

4. Create offspring $Q_{t+1}$ from $P_{t+1}$ by using crossover and mutation operators.

Note that in our study, each chromosome is constituted of $\mathrm{x}\left(\mathrm{n}_{1}, \mathrm{~m}_{1}, \tau_{1}, \mathrm{n}_{2}, \mathrm{~m}_{2}, \tau_{2}\right)$ in which $\mathrm{n}_{\mathrm{i}}$ and $\mathrm{m}_{\mathrm{i}}$ are limited to be any value in the set of $\{0, \ldots, 3\}$ and $\{1, \ldots, 4\}$, respectively. Also $\tau_{\mathrm{i}}$ is limited to be any value in the interval of $(0.25,1)$. For total controller causality, the constraint $m_{1}+m_{2}-\left(n_{1}+n_{2}\right)>3$ also has to be hold.

Chromosome $\mathrm{x}$ consists of one integer part and one floating point part. For which one-point crossover is adopted for its integer part and arithmetic crossover is adopted for the floating point part. For mutation of the chromosomes, after selecting a gene, if it belongs to integer part, it would be replaced with a random integer in a predefined set.
Otherwise, uniform mutation would be adopted. ${ }^{[24]}$ The weighting functions are set as below.

$\mathrm{F}_{\delta}(\mathrm{s})=1 /(0.3 \mathrm{~s}+1)$,

$F_{\eta}(s)=s /(0.2 s+1)$,

$\mathrm{F} \varphi(s)=1 /(0.5 s+1)$.

The obtained Pareto front is shown in Figure 6. Each solution from different parts of Pareto front brings about different system stiffness, noise reduction, and disturbance rejection. We select the solution with the gene $x(0,2,0.5,0,2,0.61)$. One may select another solution based on his own system conditions and desired performances.

\section{IMPLEMENTATION AND RESULTS}

To validate the suggested algorithm, an EW prototype is constructed. The software is written in $\mathrm{C}++$ language under RT-Linux 3.1 with the step time of $20 \mathrm{~ms}$, which is very small compared to the plant's time constant. In the interface circuit, one Intel 80C51 microcontroller is the medium between motor controllers and the software program on the computer. In the control unit, two analogue/digital chipsets (ADC07) are responsible for reading the joystick potentiometers and two digital/analogue chipsets (DAC07) are in charge of commanding two voltage-controlled oscillators located inside the motors [Figure 7].

In order to inspect time response, characteristics of the outputs and their couplings, $V_{\text {ref }}$ and $\Omega_{\text {ref }}$ are solely commanded by step signals. The tests are performed for three conditions including: (i) occupant's weight is equal to $120 \mathrm{~kg}$ and the terrain surface is dried mowed grass, (ii) occupant's weight is equal to $75 \mathrm{~kg}$ and the terrain surface is asphalt, and (iii) occupant's weight is equal to $30 \mathrm{~kg}$, and the terrain surface is tile. In Figures 8 and 9, the reference inputs $V_{\text {ref }}$ and $\Omega_{\text {ref }}$ are separately commanded by step signals with the aforementioned conditions in the presence

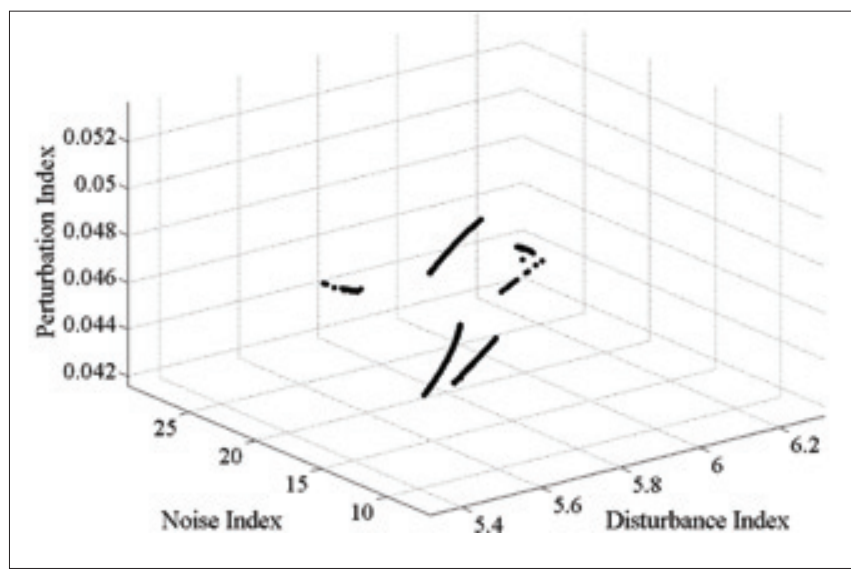

Figure 6: The obtained Pareto front for population size $\mathrm{N}=300$ and generation $T=1000$ 
and absence of the DOB.

It is obvious that the mentioned requirements in section III are satisfied. As it can be observed in Figures 8 and 9, by adding the DOB, the system stiffness is considerably improved.

The motor inputs, el and er, corresponding to Figure 8 is illustrated in Figure 10. As you can compare the leftcolumn diagrams, which are measured in the absence of DOB to the right-column diagrams, which are measured in the presence of $\mathrm{DOB}$, the amplitudes are almost the

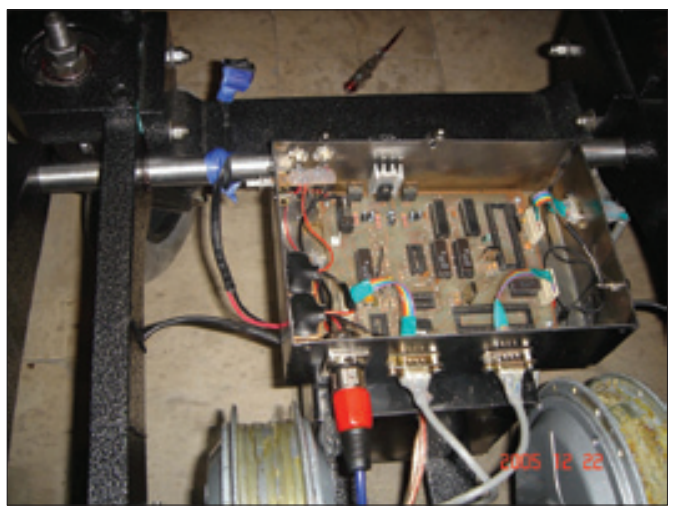

Figure 7: The control unit of our EW including two Intel 805 I microcontrollers, two ADC07 and two DAC07

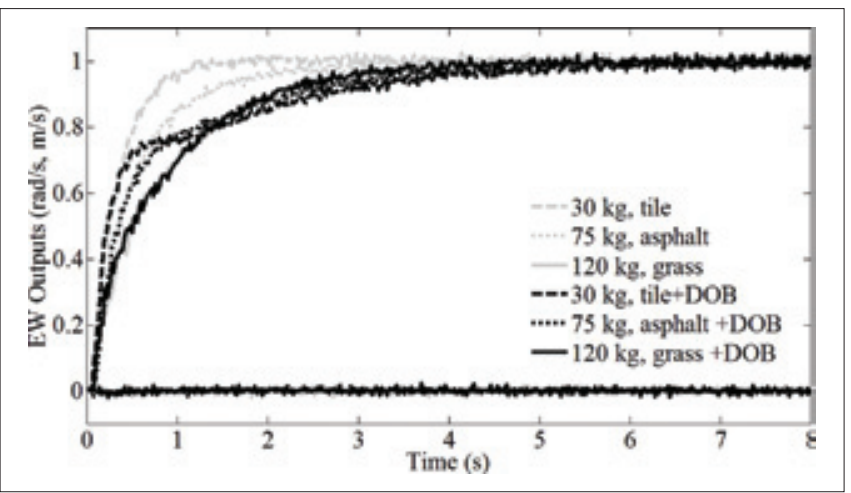

Figure 9: The EW's outputs when only the second reference input is commanded by step signal

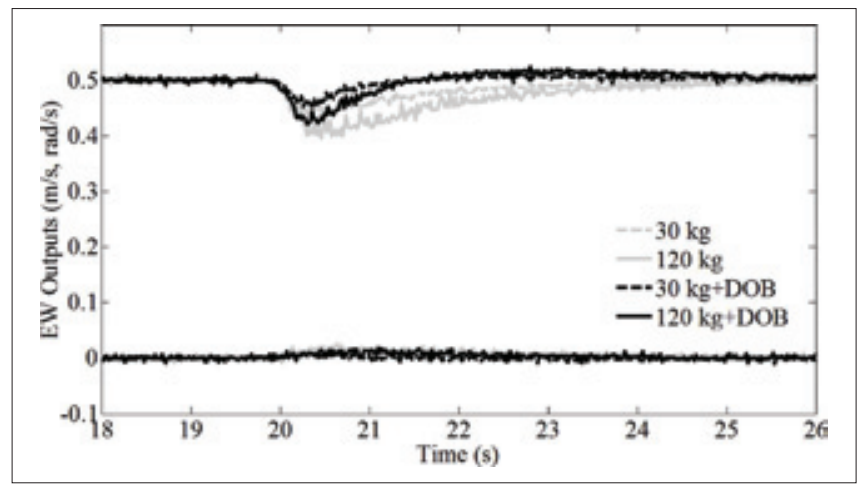

Figure I I: The EW's outputs when the EW heads directly into a slope same although the signals are relatively noisier. That phenomenon is due to greater amplitude of noise transfer function to actuator signals when the DOB is added to the control system. The same thing happens for the motor inputs corresponded to Figure 9, therefore, the diagram is not illustrated.

To study the disturbance rejection performance of the control system, the EW is driven directly into a slope in a corridor. This test is done each time with a different occupant's weight. Both situations of presence and absence of the DOB are considered. It can be seen in Figure 11 that in

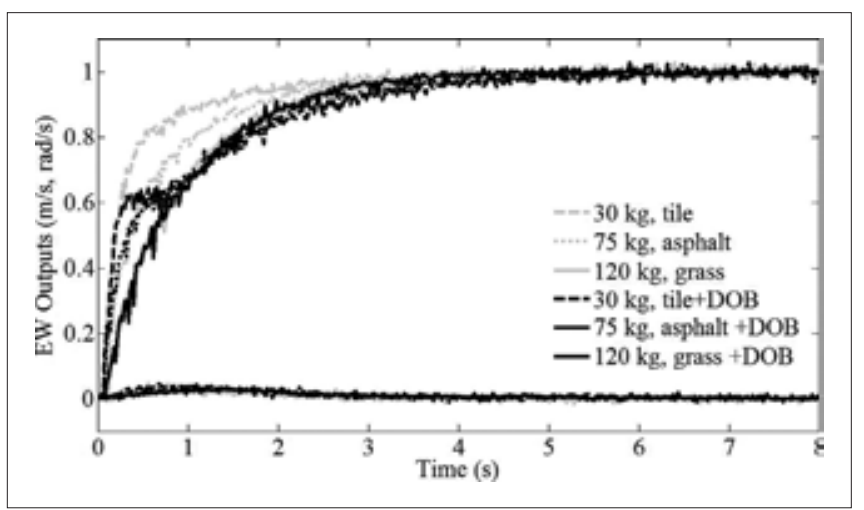

Figure 8: The EW's outputs when only the first reference input is commanded by step signal

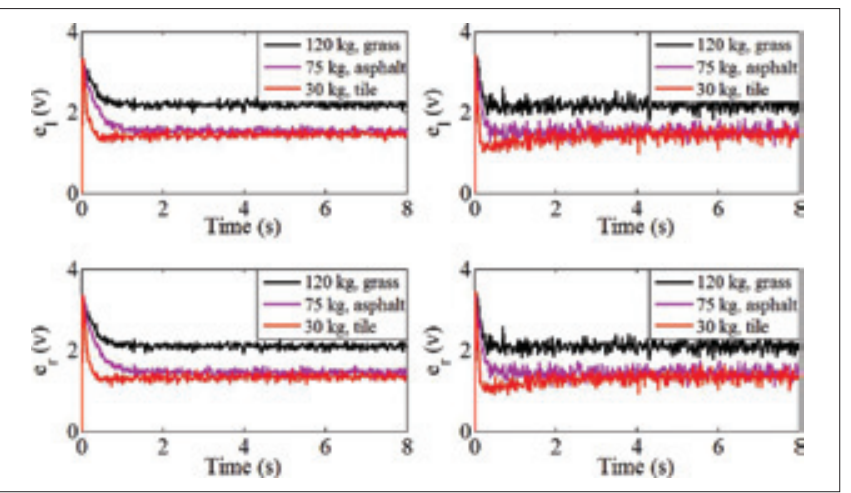

Figure 10: The EW's outputs when the EW heads directly into a slope

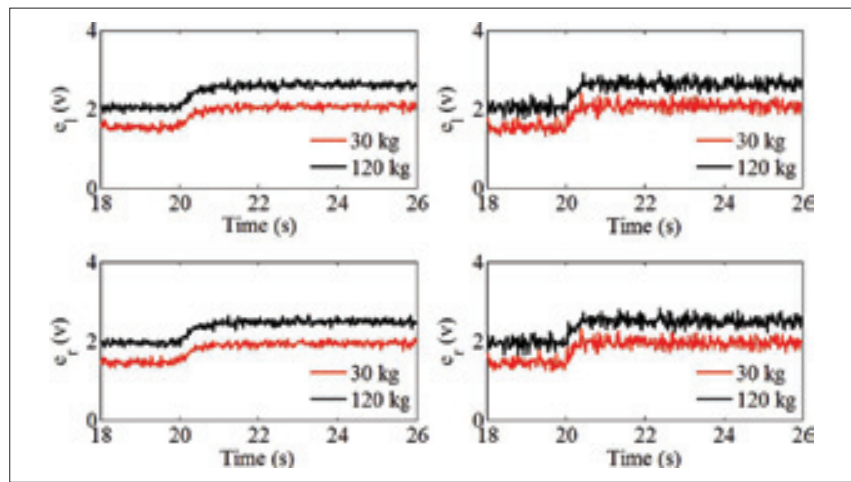

Figure 12: The EW's outputs when the EW heads directly into a slope 
every condition, the disturbance is better rejected with the proposed two-degree-of-freedom controller. Besides, the coupling among linear and angular velocities is quite low.

The corresponding motor inputs are illustrated in Figure 12. Again, the amplitudes are rather identical and relatively noisier.

\section{CONCLUSION}

In this paper, we addressed perturbations in the structure and operating environment of electric wheelchairs. The perturbations included uncertainties in the surface and the slope of the terrains where the EW might move on as well as the occupants' uncertain weights. The multivariable dynamics of the EW which took into account the effects of the slopes as additive disturbances was treated with a two-degree-of-freedom controller. The main controller was designed via the CLM and was augmented with an optimal multivariable DOB. A MOO approach using the NSGA-II was performed and six optimal design parameters were found. In this approach, more than one DOB design was obtained, so one could select a single solution based on some system performances consisting disturbance rejection, system stiffness, and noise reduction. In addition, the optimal DOB reduced sensitivity to model uncertainties, while enhancing rejection of disturbances caused due to passing through the slopes. At last, the experimental results show a noticeable improvement in system stiffness and disturbance rejection.

\section{REFERENCES}

1. Jonesand ML, Sanford JA. People with mobility impairment in the United States today and in 2010. Assistive Technology 1996;8: 43-53.

2. Johnson BW, AylorJH. Design of an adaptive controller for microcomputer implementation. IEEE Trans Ind Electron 1986;33:28-38.

3. Brown KE, Inigo RM, Johnson BW. Design, implementation, and testing of an adaptable optimal controller for an electric wheelchair. IEEE Trans Ind Appl 1990;26:1144-57.

4. Boquete L, Garcia R, Barea R, Mazo M. Neural control of the movements of a wheelchair. J Intell Robot Syst 1999;25:213-26.

5. Boquete L, Barea R, Garcia R, Mazo M, Espinosa F. Identification and control of a wheelchair using recurrent neural networks. Eng Appl Artif Intell 1999;12:443-52.

6. Boquete L, Bergasa LM, Barea R, Garcia R, Mazo M. Using a new model of recurrent neural network for control. Neural Process Lett 2001;13:101-13.

7. Boquete L, Barea R, Garcia R, Manuel Mazo, Sotelo, MA. Control of a robotic wheelchair using recurrent networks. Auton Robots 2005; 18:5-20.
8. Nguyen NT, Nguyen HT, Su S. Advanced robust tracking control of a powered wheelchair system. Conf Proc IEEE Eng Med Biol Soc 2007;2007:4767-70.

9. Kauffmann C, Zasadzinski M, Darouach M. Robust optimal control design applied to an electric wheelchair. Proc Conf Syst Man Cybern 1993;3:559-64.

10. Saadatzi MN, Poshtan J. Multivariable robust controller for linear and angular velocities of electrically-powered wheelchair using characteristic loci method. Proc IEEE Conf Control Appl 2010;2:1246-50.

11. Doyle JC, Stein G. Robust Neuro-Sliding mode multivariable control strategy for powered wheelchairs. IEEE Trans Neural Syst Rehabil Eng 2011;19:105-11.

12. Wang H, Salatin B, Grindle GG, Ding D, Cooper RA. Real-time model based electrical powered wheelchair control. Med Eng Physics 2009;31:1244-54.

13. Chin-Chih Ou, Tien-Chi Chen, Chun-Jung Chen. Design of automobile wheelchair based on fixed speed track with load torque observer. Proc. Second Int Conf Intell Netw Intell Syst 2009;27-30.

14. Sehoon Oh, Naoki H, Yoichi H. Control developments for wheelchairs in slope environments. Proc Am Control Conf 2005;2:39-744.

15. Huang W, Liu C, Hsu P, Yeh S. Precision control and compensation of servomotors and machine tools via the disturbance observer. IEEE Trans Ind Electron 2010;57:420-9.

16. Jamaludin Z, Van Brussel H, Swevers J. Friction compensation of an $\mathrm{XY}$ feed table using friction-model-based feedforward and an inverse-model-based disturbance observer. IEEE Trans Ind Electron 2009;56:3848-53.

17. Katsura S, Ohnishi K. Absolute stabilization of multimass resonant system by phase-lead compensator based on disturbance observer. IEEE Trans Ind Electron 2007;54:3389-96.

18. Katsura S, Matsumoto Y, Ohnishi K. Modeling of force sensing and validation of disturbance observer for force control. IEEE Trans Ind Electron 2007;54:530-8.

19. Mohamed YA. Design and implementation of a robust current-control scheme for a PMSM vector drive with a simple adaptive disturbance observer. IEEE Trans Ind Electron 2007;54:1981-8.

20. Yorozu Y, Hirano M, Oka K, Tagawa Y. On the robustness and performance of disturbance observers for second-order systems. IEEE Trans Automat Contr 2003;48:315-20.

21. Tesfaye A, Lee HS, Tomizuka M. A sensitivity optimization approach to design of a disturbance observer in digital motion control systems. IEEE/ASME Trans Mechatron 2000;5:32-8.

22. Macfarlane AG, Kouvaritakis B. A design technique for linear multivariable feedback systems. Int J Control 1972;25:837-74.

23. Deb K, Pratap A, Agarwal S, Meyarivan T. A fast and elitist multiobjective genetic algorithm: NSGA-II. IEEE Trans Evol Comput 2002;6:182-97.

24. Engelbrecht AP. Computational Intelligence. $2^{\text {nd }}$ ed. United States: John Wiley and Sons Ltd; 2007.

How to cite this article: Saadatzi MN, Poshtan J, Saadatzi MS. Application of MIMO disturbance observer to control of an electric wheelchair using NSGA-II. J Med Sign Sens 2011;2:122-9

Source of Support: Nil, Conflict of Interest: None declared 